\title{
Confronting the potential role of Yoga in the molecular profile of rural high-risk women for Diabetes: a pilot study
}

\author{
Navneet Kaur ${ }^{1}$, Shweta Ahuja ${ }^{2}$, Kanupriya Sharma ${ }^{3}$, Rakesh Malik ${ }^{4}$, Kavita Bakshi ${ }^{5}$, Surinder Pal ${ }^{6}$, \\ Gurmeet Singh ${ }^{7}$, Sarika Dhiman ${ }^{8}$, Kiran Sharma ${ }^{9}$, Neeru Malik ${ }^{* 10}$ \\ ${ }^{1}$ Govt. Model Sanskriti Senior Secondary School, Morni Hills, Panchkula, Haryana, India \\ ${ }^{2}$ MD Pathology, PGIMER Chandigarh, India \\ ${ }^{3}$ Dev Samaj College of Education, Sector 36-B, Chandigarh, India \\ ${ }^{4}$ Department of Neurology, Neuroscience Research Lab, Postgraduate Institute of Medical Education and Research, Chandigarh, India \\ ${ }^{5}$ Deputy Director Physical Education and Sports, Panjab University, Chandigarh, India \\ ${ }^{6}$ Department of Allied and Applied Sciences, University of Patanjali, Haridwar, Uttarakhand, India \\ ${ }^{7}$ Centre for Systems Biology and Bioinformatics, Panjab University, Chandigarh, India \\ ${ }^{8}$ Department of Physical Education, Panjab University, Chandigarh, India \\ ${ }^{9}$ Goswami Ganesh Dutta Sanatan Dharma College, Chandigarh, India \\ ${ }^{10}$ Yoga Federation of India, Chandigarh, India
}

\section{KEY WORDS}

Diabetic Yoga Protocol

Indian Diabetes Risk Score

Prediabetes

Angiogenesis

Neurogenesis.
*Corresponding Author:

Neeru Malik, PhD

Dev Samaj College of Education

Sector 36B, Chandigarh, India

Contact no: +91-9781133666

E-mail: drneerumalikhry@gmail.com

\begin{abstract}
Background and purpose: Yoga has been shown to have established beneficial impact through many previous studies. The mind-body practices like Yoga have an ameliorating effect on diabetes and prediabetes. The majority of prior published literature focused their attention on the glucose parameters in diabetic and prediabetic pathology. The purpose of the present pilot study is to explore the effect of AYUSH-approved Diabetic Yoga Protocol (DYP) on selected angiogenesis and neurogenesis markers in high-risk rural women for Diabetes.

Methods: Total 15 high-risk women for Diabetes were selected from rural area of Chandigarh, for a 3-month DYP intervention. The pre-post single group experimental research design was implemented in the study. The changes in angiogenesis, neurogenesis parameters, and leptin were assessed at baseline and after 3 months after DYP intervention.

Results: The result of the present study revealed that after 3 months of DYP intervention the statistically significant improvements were noticed on serum VEGF levels $(p=0.039)$. The improvements in angiogenin and BDNF levels were also seen after DYP practice.

Conclusion: The results highlight the potential role of DYP on cellular growth and neuronal survival.

Keywords: Diabetic Yoga Protocol, Indian Diabetes Risk Score, Prediabetes, angiogenesis, neurogenesis.
\end{abstract}

doi: 10.38205/imcr.020238

\section{Introduction}

Diabetes is a metabolic disease, which is progressing dramatically worldwide. According to the data revealed by the International Diabetes Federation, 2017, India is having the most diabetic cases (77 million in 2019) in the world after China (1). Diabetes is a condition that deteriorates with increasing levels of glucose in the blood. The hyperglycemic condition in the blood occurs mainly due to insufficient insulin production and insulin's impaired action from pancreatic $\beta$ cells (2-3). The presence of high levels of glucose in blood is controlled by anti-diabetic drugs and through alterations and modifications in individual's lifestyle. Prediabetes is a stage that acts as an alarm to being aware of the glycemic status or taking preventive measures to avoid the Diabetic condition. In prediabetes, the blood glucose levels falls between normal glycemia and hyperglycemia (4). Diabetes which is considered to be the breeding ground to various microvascular and macrovascular complications is at the initial stage in prediabetic condition
(4-5). Therefore, by ensuring preventive measures at the prediabetic stage, might also help in effectively handling the initial phase of various microvascular and macrovascular complications. Mohan et al. 2005 developed the Indian Diabetes Risk Score (IDRS) which is an economical tool for screening out high-risk individuals for Diabetes (6). There may be lesser conversion rates from prediabetics to diabetics if people know their risk status for the disease and take up timely preventive measures. Yoga is also one of the lifestyle modification tools which works primarily on the preventive aspect of the disease. Despite best advances in modern medical science the incidence of Diabetes is increasing at alarmingly high rate but Yoga is proving to be an impressive alternative. Understanding the importance of Yoga in controlling Diabetes Prime Minister of India urged to promote Yoga to control Diabetes on 2nd International Day of YOGA celebration at Chandigarh. As instructed the Ministry of Ayush started a few programmes to enhance countrywide diabetes awareness. Under the chairmanship of Dr H R Nagendra a common Diabetic Yoga Protocol (DYP) 
based on traditional scripts and researches was made by using Delphi protocol by a group of experts to further the countrywide efforts to control the menace of Diabetes. The beneficial role of Yoga on various disease conditions is well elucidated in the earlier published works of literature. Studies have shown that Yoga is an established lifestyle intervention mode in managing cardiovascular diseases and has led to reduction in mortality \& morbidity associated with this disease (7). Also a systematic review done by Holger Cramer et al has found that there is strog evidence to support the fact that Yoga positively affects pulmonary function and exercise capacity in COPD (Chronic obstructive pulmonary disease) patients (8). In another metanalysis Yoga has been shown to be an alternative in diabetes prevention and helps improve glycemic control along with other health parameters in the prediabetic population (9). The previous published literature focused their attention primarily on the glycemic aspect in the diabetic and prediabetic pathology. There are lacunae in the literature that focused upon the various molecular pathways associated with diabetes pathology. However, these studies showed the beneficial role of Yoga on angiogenesis and neurogenesis (10). The angiogeneis and neurogensis molecular pathways are associated with diabetes. The angiogenesis markers e.g. vascular endothelial growth factor (VEGF) \& angiogenin and neurogenesis marker i.e brain-derived neurotropic factor (BDNF) play a prominent role in diabetic pathology. The increase and decrease in the angiogenesis rate leads to Diabetic retinopathy and delays in wound healing respectively. (11-12). The Brain-derived neurotropic factor (BDNF) is related with memory, cognition, concentration (13). The decrease in BDNF levels is linked with various neurological disorders like Stress, tension, depression, and Alzheimer's disease which are also associated with Diabetic pathology (14). Leptin is a hormone that regulates the appetite in the individual (15) and inappropriate functioning of the Leptin hormone is also associated with Diabetes and Prediabetes. (16-17) The previous studies based on the diabetic and prediabetic pathophysiology primarily studied the glycemic parameters. The objective of this study is to investigate or understand the effect of Diabetic Yoga Protocol (DYP) on molecular markers of rural high-risk women for Diabetes.

\section{Method and Procedure}

In this study, a single group pre-post experimental design was used. For achieving the objective of the present study door to door survey was conducted in rural areas i.e. Village Dhanas for the detection of high-risk women for diabetes. The detailed flow chart of the study design is also shown in Figure 1. For pilot study, those females who had scored above 60 on the IDRS were recruited in the present study. Total 15 rural, high-risk women with potential Diabetes have completed the study after the removal of dropouts. The enrolled participant underwent three months DYP intervention as shown in Table 1. A certified Yoga instructor took the DYP sessions. During all this period of intervention compliance \& adherence to the protocol was checked by marking \& maintaining daily

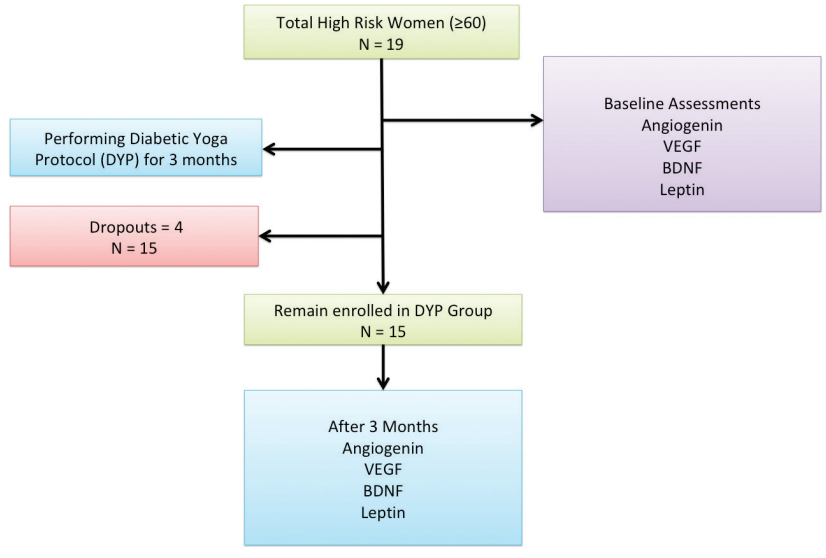

Fig. 1: Flow chart of study design.

Table 1: Diabetic Yoga Protocol

\begin{tabular}{|c|c|c|}
\hline $\begin{array}{l}\text { Sr. } \\
\text { No }\end{array}$ & Name of Practice & $\begin{array}{c}\text { Duration } \\
\text { (min) }\end{array}$ \\
\hline 1 & Starting Prayer: Asatoma Sadgamaya & 2 \\
\hline 2 & $\begin{array}{l}\text { Preparatory Sukshma Vyayamas and } \\
\text { Shithilikarna Practices } \\
\text { 1. Urdhavahastashvasan (Hand stretching breathing } \\
3 \text { rounds at } 90^{\circ}, 135^{\circ} \text { and } 180^{\circ} \text { each) } \\
\text { 2. Kati-Shakti Vikasaka ( } 3 \text { rounds) } \\
\text { a) Forward and Backward Bending b) Twisting } \\
\text { 3. Sarvangapushti ( } 3 \text { rounds clockwise, } 3 \text { rounds } \\
\text { anticlockwise) }\end{array}$ & 6 \\
\hline 3 & $\begin{array}{l}\text { Surya Namaskara (SN) } \\
10 \text { step fast Surya Namaskara } 6 \text { rounds } \\
12 \text { step slow Surya Namaskara } 1 \text { round } \\
\text { Modified version Chair SN } 7 \text { rounds } \\
\end{array}$ & 9 \\
\hline 4 & $\begin{array}{l}\text { Asanas (1min per Asana) } \\
\text { 1. Standing Position (1min per Asana) } \\
\text { Trikonasana, Parvritta Trikonasana, Prasarita } \\
\text { Padhastasana } \\
\text { 2. Supine Position } \\
\text { Jatara Parivartanasana, Pawanmuktasana, } \\
\text { Viparitakarani } \\
\text { 3. Prone Position } \\
\text { Bhujangasana, Dharuasana followed by Pawan- } \\
\text { muktasana } \\
\text { 4. Sitting Position } \\
\text { Mandukasana, Vakrasana/Ardhamatsayendrasana, } \\
\text { Paschimatanasana, Ardha Ushtrasana } \\
\text { At the end, relaxation with abdominal breathing in the } \\
\text { supine position (vishanti), 10-15 rounds (2 minutes) }\end{array}$ & 15 \\
\hline 5 & $\begin{array}{l}\text { Kriya } \\
\text { a. Agnisara: } 1 \text { minute b. Kapalabhati ( } 60 \text { breaths per } \\
\text { minute for } 1 \text { minute followed by rest for } 1 \text { minute) }\end{array}$ & 3 \\
\hline 6 & $\begin{array}{l}\text { Pranayama } \\
\text { Nadishuddhi (for } 6 \text { minutes, with antarkumbhak and } \\
\text { jalandhar bandh for } 2 \text { seconds) } \\
\text { Brahmari } 3 \text { minutes }\end{array}$ & 9 \\
\hline 7 & $\begin{array}{l}\text { Meditation (for Stress, for deep relaxation and } \\
\text { silencing of mind) } \\
\text { Cyclic Meditation }\end{array}$ & 15 \\
\hline 8 & Resolve (I am Completely Healthy) & 1 \\
\hline 9 & Closing Prayer: Sarvebhavantu Sukhina............. & 1 \\
\hline & Total duration & 60 \\
\hline
\end{tabular}


attendance sheet. The assessments for selected molecular markers i.e. Angiogenin, VEGF, BDNF, and Leptin were taken at baseline and after 3 months. The estimation of the protein levels for selected molecular markers (Angiogenin, VEGF, BDNF, and Leptin) was done by ELISA (enzyme-linked immunosorbent assay) as per manufacturers instructions. The study was approved by the Panjab University Institutional Ethics Committee (PUIEC) vide letter no. PUIEC/2017/80/A-1/08/08.

\section{Statistical Procedure}

The Statistical package for social sciences (SPSS) was used. Firstly, the normality of the data was checked through
Kolmogorov-Smirnov (KS) test. All the selected variables were found to be normally distributed ( $p>0.05$ ). The paired t-test was used to find out the changes at baseline and after three months of DYP practice.

\section{Results}

The result revealed in the Table 2 shows that statistical significant improvement was seen on VEGF ( $p=0.039)$ concentrations after DYP intervention. Moreover, the improvement in the angiogenin and BDNF levels of the participant was seen but not at a significant level. However, no significant changes were seen on the Leptin level of the participants.

Table 2: Pre-Post test mean comparison in DYP group on selected molecular markers i.e. Angiogenin, VEGF, BDNF and Leptin in mean, SD, mean difference, and t- value with p-values.

\begin{tabular}{|c|c|c|c|c|c|c|c|c|}
\hline \multirow[t]{2}{*}{ Variables } & \multirow{2}{*}{$\begin{array}{l}\text { Test } \\
\text { Condition }\end{array}$} & \multirow[t]{2}{*}{ Mean } & \multirow[t]{2}{*}{ SD } & \multicolumn{2}{|c|}{$95 \%$ CI } & \multirow[t]{2}{*}{ t-value } & \multirow[t]{2}{*}{ p-value } & \multirow[t]{2}{*}{$\%$ Change } \\
\hline & & & & Lower & Upper & & & \\
\hline \multirow{2}{*}{ Angiogenin } & Pre-test & 1.109 & 0.648 & \multirow{2}{*}{-1.253} & \multirow{2}{*}{0.056} & \multirow{2}{*}{-1.96} & \multirow{2}{*}{0.07} & \multirow{2}{*}{$53.92 \%$} \\
\hline & Post-test & 1.707 & 1.146 & & & & & \\
\hline \multirow{2}{*}{ VEGF } & Pre-test & 0.014 & 0.013 & \multirow{2}{*}{-0.010} & \multirow{2}{*}{-0.0003} & \multirow{2}{*}{-2.27} & \multirow{2}{*}{$0.039 *$} & \multirow{2}{*}{$35.71 \%$} \\
\hline & Post-test & 0.019 & 0.016 & & & & & \\
\hline \multirow{2}{*}{ BDNF } & Pre-test & 112.77 & 151.811 & \multirow{2}{*}{-137.101} & \multirow{2}{*}{20.292} & \multirow{2}{*}{-1.60} & \multirow{2}{*}{0.133} & \multirow{2}{*}{$51.78 \%$} \\
\hline & Post-test & 171.17 & 244.485 & & & & & \\
\hline \multirow{2}{*}{ Leptin } & Pre-test & 0.0004 & 0.00052 & \multirow{2}{*}{-0.0002} & \multirow{2}{*}{0.0001} & \multirow{2}{*}{-0.66} & \multirow{2}{*}{0.518} & \multirow{2}{*}{$25 \%$} \\
\hline & Post-test & 0.0005 & 0.00044 & & & & & \\
\hline
\end{tabular}

Data is presented in mean, $\mathrm{SD}$, mean difference, and statistical significance $\left(p=0.07^{*}, p=0.39^{*}\right)$, $\mathrm{P}$ value $<0.05$ were considered significant. Three months changes were seen in DYP and Control group by paired t-test. VEGF = Vascular Endothelial Growth Factor, BDNF = Brain Derived Neurotropic Factor, SD = Standard Deviation, $\mathrm{CI}=$ Confidence Interval, DYP $=$ Diabetic Yoga Protocol.

\section{Discussion}

Diabetes is a metabolic disorder, which is also dependent on the lifestyle of the individual. The timely preventive measures could help in preventing or delaying the onset of Diabetes. Specifically, in the prediabetic stage, non-pharmacological approaches like physical activity, Yoga, and Dietary modifications are required to delay the development from prediabetes to diabetes. A study done by Anjana et al. revealed that the prevalence of prediabetes was slightly higher in rural areas $(14.7 \%)$ of Chandigarh in comparison with urban areas (14.5\%) (18). Ramchandran et al. reported 14\% prevalence of prediabetes in the Indian population (19). Further, Kumar et al. also revealed the prevalence of diabetes and prediabetes in a joint population of Chandigarh \& Panchkula with $12.67 \%$ and $11.69 \%$ respectively (20). Moreover, in the Asian Indian population, the risk for conversion from prediabetic to a diabetic is more vulnerable in comparison with the other ethnic population groups (21-22).

There is a lack of literature regarding the impact of Yoga on the molecular aspect specifically in the prediabetic population. The present pilot study focuses upon the impact of AYUSH-approved, Diabetic Yoga Protocol on molecular markers. The result of the present pilot study shows the beneficial impact of Yoga on angiogenesis and neurogenesis markers. The statistically significant elevation was seen on VEGF concentrations after 3 months of DYP practice. The previous reports show an increase in VEGF level after physical activity or Yoga (23). Interestingly, the increase in angiogenin levels and BDNF levels were seen with $53.92 \%$ and $51.78 \%$ respectively but no at a significant level.

The impact of Yoga on angiogenin levels is not yet widely elucidated in the previous literature. However, Sharma et al., in their study showed the positive impact of Common Yoga Protocol on angiogenin levels (10). BDNF which is the key marker for neurogenesis and responsible for various cognitive, memory-related activities in the body proves to be improved in the literature done in the past (24-25). The elevated level of BDNF is also synchronized or connected with the psychological health of the individual (25). The VEGF is the key marker that works as a joining channel between angiogenesis and neurogenesis (26-28). Leptin shows no significant changes after DYP intervention. However, the expression of Leptin slightly increases after the DYP intervention. The result of the study attributed to the fact that no dietary control was adopted in the present pilot study. However, the studies done in the past show an increase (29) or decrease (30) in the serum Leptin levels. 
The glycemic parameters, anthropometric parameters are often considered as associated with diabetes and prediabetes. However, neuronal and cellular growth might also play the important role in the pathophysiology of diabetes and prediabetes. Diabetes and prediabetes not only associated with glycemic parameters but it may also connect with neuronal and cellular growth. Our pilot study shows the beneficial role of Yoga on angiogenesis and neurogenesis markers, which further open the new outlooks for better understanding of angiogenesis and neurogenesis in the diabetic pathology.

The present pilot study shows the impact of non-pharmacological approaches like yoga and meditative practices on molecular makers related with angiogenesis and neurogenesis. It further highlights the need for conducting the long term studies on angiogenesis and neurogenesis pathways in the larger population.

\section{Conclusion}

The present pilot study shows the efficacy of Diabetic Yoga protocol on angiogenesis and neurogenesis levels in high-risk women for Diabetes. The efficacy of DYP in neuronal and cellular growth might helps in a better understanding of diabetic and prediabetic pathology.

\section{Acknowledgment}

The authors would like to thanks the University Grants Commission (UGC) for supporting this research. The authors acknowledge Dr. Davinder Dhawan, and Bhai Ghaniya ji (BGJ) institute of health, Panjab University, Chandigarh for help in the conduct of the study. The authors would thankful to all the study participants for their participation in the study.

\section{Authors contributions}

NK: writing, experimentation,analysis of Data, data collection SA: writing, editing

KS: Experimentation

RM: Editing, Writing, Co- Conceptualization

KB: Data Collection, writing

SP: Validation of Data

GS: Editing of manuscript

SD: Data Collection

KS: Data Collection

NM: Conceptualization, study design, Editing.

\section{Source of funding}

This study has been supported by the University Grants Commission (UGC) via Letter No. 15-9(June 2014)/2014(NET).

\section{Conflict of interest}

The authors declare no conflict of interest.

Received Date: 30-06-21; Revised Date: 27-07-21

Accepted Date: 28-07-21

\section{References}

1. Saeedi P, Petersohn I, Salpea P, Malanda B, Karuranga S, Unwin N, Colagiuri S, Guariguata L, Motala AA, Ogurtsova K, Shaw JE. Global and regional diabetes prevalence estimates for 2019 and projections for 2030 and 2045: Results from the International Diabetes Federation Diabetes Atlas. Diabetes research and clinical practice. 2019 Nov 1; 157: 107843

2. Pal DK, Bhalla A, Bammidi S, Telles S, Kohli A, Kumar S, Devi P, Kaur N, Sharma K, Kumar R, Malik N. Can yoga-based diabetes management studies facilitate integrative medicine in india current status and future directions. Integrative Medicine International. 2017; 4(3-4): 125-41.

3. Ta S. Diagnosis and classification of diabetes mellitus. Diabetes care. 2014 Jan 1; 37(1): 81-90.

4. Edwards CM, Cusi K. Prediabetes: a worldwide epidemic. Endocrinology and Metabolism Clinics. 2016 Dec 1; 45(4): 751-64.

5. Wilson ML. Prediabetes: beyond the borderline. Nursing Clinics. 2017 Dec 1; 52(4): 665-77.

6. Mohan V, Deepa R, Deepa M, Somannavar S, Datta M. A simplified Indian Diabetes Risk Score for screening for undiagnosed diabetic subjects. Journal of the Association of Physicians of India. 2005; 53: 759-63.

7. Guddeti RR, Dang G, Williams MA, Alla VM. Role of yoga in cardiac disease and rehabilitation. Journal of cardiopulmonary rehabilitation and prevention. 2019 May 1; 39(3): 146-52.

8. Cramer H, Haller H, Klose P, Ward L, Chung VC, Lauche R. The risks and benefits of yoga for patients with chronic obstructive pulmonary disease: a systematic review and meta-analysis. Clinical rehabilitation. 2019 Dec; 33(12): 1847-62.

9. Ramamoorthi R, Gahreman D, Skinner T, Moss S. The effect of yoga practice on glycemic control and other health parameters in the prediabetic state: A systematic review and meta-analysis. PloS one. 2019 Oct 16; 14(10): e0221067.

10. Sharma K, Pannu V, Sayal N, Bhalla A, Anand A. Effects of one month of Common Yoga Protocol practice appear to be mediated by the angiogenic and neurogenic pathway: A pilot study. EXPLORE. 2020 Sep 25.

11. Cheng R, Ma JX. Angiogenesis in diabetes and obesity. Reviews in Endocrine and Metabolic Disorders. 2015 Mar; 16(1): 67-75.

12. Martin A, Komada MR, Sane DC. Abnormal angiogenesis in diabetes mellitus. Medicinal research reviews. 2003 Mar; 23(2): 117-45.

13. Huang T, Larsen KT, Ried-Larsen M, Møller NC, Andersen LB. The effects of physical activity and exercise on brain-derived neurotrophic factor in healthy humans: A review. Scandinavian journal of medicine \& science in sports. $2014 \mathrm{Feb}$; 24(1): 1-0.

14. Borroni B, Grassi M, Archetti S, Costanzi C, Bianchi M, Caimi L, Caltagirone C, Di Luca M, Padovani A. BDNF genetic variations increase the risk of Alzheimer's disease-related depression. Journal of Alzheimer's Disease. 2009 Jan 1; 18(4): 867-75.

15. Klok MD, Jakobsdottir S, Drent ML. The role of leptin and ghrelin in the regulation of food intake and body weight in humans: a review. Obesity reviews. 2007 Jan; 8(1): 21-34.

16. Tanizawa Y, Okuya S, Ishihara H, Asano T, Yada T, Oka Y. Direct stimulation of basal insulin secretion by physiological concentrations of leptin in pancreatic $\beta$ cells. Endocrinology. 1997 Oct 1; 138(10): 4513-6.

17. Seufert J, Kieffer TJ, Leech CA, Holz GG, Moritz W, Ricordi C, Habener JF. Leptin suppression of insulin secretion and gene expression in human pancreatic islets: implications for the development of adipogenic diabetes mellitus. The Journal of Clinical Endocrinology \& Metabolism. 1999 Feb 1; 84(2): 670-6.

18. Anjana RM, Pradeepa R, Deepa M, Datta M, Sudha V, Unnikrishnan R, Bhansali A, Joshi SR, Joshi PP, Yajnik CS, Dhandhania VK. Prevalence of diabetes and prediabetes (impaired fasting glucose and/or impaired glucose tolerance) in urban and rural India: Phase I results of the Indian Council of Medical Research-India Diabetes (ICMR-INDIAB) study. Diabetologia. 2011 Dec; 54(12): 3022-7. 
19. Ramachandran A, Snehalatha C, Kapur A, Vijay V, Mohan V, Das AK, Rao PV, Yajnik CS, Kumar KP, Nair JD. High prevalence of diabetes and impaired glucose tolerance in India: National Urban Diabetes Survey. Diabetologia. 2001 Sep; 44(9): 1094-101.

20. Kumar S, Anand A, Nagarathna R, Kaur N, Sivapuram MS, Pannu V, Pal DK, Malik N, Singh AK, Nagendra HR. Prevalence of prediabetes, and diabetes in Chandigarh and Panchkula region based on glycated haemoglobin and Indian diabetes risk score. Endocrinology, Diabetes \& Metabolism.: e00162.

21. Anjana RM, Rani CS, Deepa M, Pradeepa R, Sudha V, Nair HD, Lakshmipriya N, Subhashini S, Binu VS, Unnikrishnan R, Mohan V. Incidence of diabetes and prediabetes and predictors of progression among Asian Indians: 10-year follow-up of the Chennai Urban Rural Epidemiology Study (CURES). Diabetes care. 2015 Aug 1; 38(8): 1441-8.

22. Sattar N, Gill JM. Type 2 diabetes in migrant south Asians: mechanisms, mitigation, and management. The lancet Diabetes \& endocrinology. 2015 Dec 1; 3(12): 1004-16.

23. Vital TM, Stein AM, de Melo Coelho FG, Arantes FJ, Teodorov E, SantosGalduróz RF. Physical exercise and vascular endothelial growth factor (VEGF) in elderly: A systematic review. Archives of gerontology and geriatrics. 2014 Sep 1; 59(2): 234-9.

24. Cahn BR, Goodman MS, Peterson CT, Maturi R, Mills PJ. Yoga, meditation and mind-body health: increased BDNF, cortisol awakening response, and altered inflammatory marker expression after a 3-month yoga and meditation retreat. Frontiers in human neuroscience. 2017 Jun 26; 11: 315.

25. Halappa NG, Thirthalli J, Varambally S, Rao M, Christopher R, Nanjundaiah GB. Improvement in neurocognitive functions and serum brain-derived neurotrophic factor levels in patients with depression treated with antidepressants and yoga. Indian journal of psychiatry. 2018 Jan; $60(1): 32$.

26. Carmeliet P, Jain RK. Molecular mechanisms and clinical applications of angiogenesis. Nature. 2011 May; 473(7347): 298-307.

27. Cao L, Jiao X, Zuzga DS, Liu Y, Fong DM, Young D, During MJ. VEGF links hippocampal activity with neurogenesis, learning and memory. Nature genetics. 2004 Aug; 36(8): 827-35

28. Fabel K, Fabel K, Tam B, Kaufer D, Baiker A, Simmons N, Kuo CJ, Palmer TD. VEGF is necessary for exercise-induced adult hippocampal neurogenesis. European Journal of Neuroscience. 2003 Nov; 18(10): 2803-12.

29. Telles S, Sharma SK, Yadav A, Singh N, Balkrishna A. A comparative controlled trial comparing the effects of yoga and walking for overweight and obese adults. Medical science monitor: international medical journal of experimental and clinical research. 2014; 20: 894.

30. Telles S, Naveen VK, Balkrishna A, Kumar S. Short term health impact of a yoga and diet change program on obesity. Medical Science Monitor. 2009 Dec 21; 16(1): CR35-40. 